Cite as: Lomas, T., Medina, J. C., Ivtzan, I., Rupprecht, S., \& Eiroa-Orosa, F. J. (2018). Mindfulness-based interventions in the workplace: An inclusive systematic review and meta-analysis of their impact upon wellbeing. The Journal of Positive Psychology, in press. https://doi.org/10.1080/17439760.2018.1519588

\title{
Mindfulness-based interventions in the workplace: An inclusive meta-analysis of their impact upon wellbeing
}

Tim Lomas $^{1 \dagger}$, Juan Carlos Medina ${ }^{2}$, Itai Ivtzan ${ }^{1}$, Silke Rupprecht ${ }^{3}$, Francisco José EiroaOrosa $^{2}$

${ }^{1}$ School of Psychology, University of East London, Arthur Edwards Building, Water Lane, London, E15 4LZ, United Kingdom

${ }^{2}$ Section of Personality, Evaluation and Psychological Treatment, Department of Clinical Psychology and Psychobiology, Faculty of Psychology, Institut de Neurociències, Universitat de Barcelona, Pg. Vall d'Hebron, 171, 08035 Barcelona, Spain.

${ }^{3}$ Leuphana University, Scharnhorststraße 1, 21335 Lüneburg, Germany

${ }^{\dagger}$ Author responsible for correspondence:

Email: t.lomas@uel.ac.uk 
Running title: Mindfulness in the workplace

Mindfulness-based interventions in the workplace: An inclusive systematic review and meta-analysis of their impact upon wellbeing

\begin{abstract}
Given the demanding nature of many professions, efforts are ongoing to develop initiatives to improve occupational wellbeing, including mindfulness-based interventions (MBIs). To assess the efficacy of MBIs, meta-analytic procedures were conducted on 35 randomized controlled trials derived from an earlier inclusive systematic literature search (covering all occupations, MBIs, and wellbeing-related outcomes). Mindfulness had significant moderate effects on deficit-based outcomes such as stress $(S M D=-0.57)$, anxiety $(S M D=-0.57)$, distress $(S M D=$ $-0.56)$, depression $(S M D=-0.48)$, and burnout $(S M D=-0.36)$, and significant moderate to small effects on asset-based outcomes like health $(S M D=0.63)$, job performance $(S M D=$ $0.43)$, compassion and empathy $(S M D=0.42)$, mindfulness $(S M D=0.39)$, and positive wellbeing $(S M D=0.36)$, while no significant effects were observed for depression or emotional regulation. However, the quality of the studies was inconsistent, suggesting more high-quality randomised controlled trials are needed.
\end{abstract}

Keywords: mindfulness; meditation; occupational; wellbeing; meta-analysis. 
Running title: Mindfulness in the workplace

\section{Introduction}

The demanding nature of work, and its impact upon wellbeing, is of increasing concern worldwide. For instance, in an analysis of occupational mental health in the United States, Goh, Pfeffer, and Zenios (2015) identified multiple source of work-related stress, some of which are directly relate to occupational dynamics (e.g., long hours, lack of control, and job insecurity), and some of which extend beyond the workplace (e.g., work-family conflict, lack of health insurance, and layoffs or unemployment). Similarly, in the United Kingdom, the Health and Safety Executive (2016) identified multiple factors contributing to work-related stress (and concomitant mental health issues, such as depression or anxiety), including workload pressures, tight deadlines, lack of managerial support, and burdens of excessive responsibility. Such burdens are widely experienced (see Hassard et al. (2018) for a recent systematic review). For instance, the Fifth European Working Conditions Survey (Eurofound, 2012) found that $22 \%$ of European workers reported experiencing work-related stress, with many more exposed to the psychosocial risks of such stress (including 62\% reported working under tight deadlines, $59 \%$ at a fast pace, $51 \%$ experiencing organizational change, and $24 \%$ working more than 40 hours a week). Moreover, a survey of 31 European countries reported that $40 \%$ of workers felt that stress was not handled or managed well in their workplace (EU-OSHA, 2013).

The wellbeing-related consequences of these factors present a serious problem obviously for the sufferers themselves, and also for their employers and the wider economy. Goh et al. (2015) estimate that, in the United States, workplace stress may contribute to annually at least 120,000 deaths and cost up to $\$ 190$ billion dollars (around $8 \%$ of national spending on healthcare). Relatedly, in the European Union, an analysis by Matrix (2013) estimated the annual cost of work-related depression alone to be $€ 617$ billion annually (comprising €272 billion from absenteeism and presenteeism, €242 billion from loss of productivity, $€ 63$ billion from health care costs, and $€ 39$ billion from disability benefit 
Running title: Mindfulness in the workplace

payments). Moreover, there are indications that work-related challenges are becoming increasingly demanding. By way of example, in the United Kingdom, while the prevalence of mental illness in the general population has not significantly increased in the last twenty years (ONS, 2014), the number of sick days lost to mental ill-health has increased by $24 \%$ since 2009 (Davies, 2014).

Given that context, a nexus of intersecting interests is converging to help develop initiatives to ameliorate work-related mental health issues (George, Dellasega, Whitehead, \& Bordon, 2013). Such programmes have been found to be generally effective overall: for instance, the Matrix (2013) analysis examined a range of initiatives and calculated their net economic benefits over a 1 -year period to range between $€ 0.81$ and $€ 13.62$ for every $€ 1$ of expenditure in the programme (via reducing pressures on healthcare systems, social welfare systems, employers, and the economy as a whole). Over recent years, among the most prominent of these work-related programmes are those involving mindfulness meditation mindfulness-based interventions (MBIs) - which are the focus of this review.

\section{Mindfulness}

Originating in the context of Buddhism around the $5^{\text {th }}$ century BCE, mindfulness came to prominence in the West through Kabat-Zinn (1982), who devised a Mindfulness-Based Stress Reduction (MBSR) programme for chronic pain. Mindfulness can refer to both: (1) a state or quality of mind; and (2) a meditation practice designed to foster this. The pre-eminent operationalisation of mindfulness as a state/quality is Kabat-Zinn's (2003, p.145) definition: "the awareness that arises through paying attention on purpose, in the present moment, and nonjudgmentally to the unfolding of experience moment by moment." Then, as per the second meaning of mindfulness, there are meditation practices which facilitate this state.

Meditation refers generically to mental activities which share in common a focus on training the self-regulation of attention and awareness, thereby enhancing voluntary control of 
Running title: Mindfulness in the workplace

mental processes (Lomas, Ivtzan, \& Fu, 2015). A key mechanism through which mindfulness specifically is theorised to exert its beneficial effects is "reperceiving" (Shapiro, Carlson, Astin, and Freedman, 2006), also known as "decentring." This is a "fundamental shift in perspective," in which instead of our habitual tendency to be "immersed in the personal drama or narrative of our life story, we are able to stand back and witness it" (p.377). Thus, in practising mindfulness, people learn how to “observe one's thoughts and feelings as temporary, objective events in the mind, as opposed to reflections of the self that are necessarily true" (Fresco et al., 2007, p.234). MBIs therefore help "retrain" awareness, giving people more choice in how they relate and respond to their subjective experience, rather than habitually responding in unhelpful ways (Chambers, Gullone, \& Allen, 2009, p.659). The positive impact of retraining awareness in this way extends to mental health generally. Decentring helps people tolerate distressing qualia, which matters since inability to tolerate such qualia is a transdiagnostic factor underlying diverse mental health issues (Aldao, Nolen-Hoeksema, \& Schweizer, 2010).

\section{Mindfulness in the workplace}

MBIs were initially developed for clinical contexts. For instance, Kabat-Zinn's (1982) prototypical MBSR program was designed for the treatment of chronic pain, before being adapted for other physical and mental health conditions, such as anxiety (Vøllestad, Sivertsen, \& Nielsen, 2011). Subsequently, related clinical interventions adapted the MBSR protocol for various other physical and mental health problems, such as Mindfulness-Based Cognitive Therapy (MBCT) for recurrent depression (Segal, Williams, \& Teasdale, 2002). Then, over recent years, there has been increasing interest in the deployment of MBIs in occupational contexts, not only for staff suffering mental health issues, but for workers "in general" (e.g., as a protective measure against future issues). This emergent literature on mindfulness in the workplace has been analysed in numerous recent systematic reviews (occasionally accompanied by meta-analyses). Generally speaking, the results have been encouraging, 
Running title: Mindfulness in the workplace

suggesting that mindfulness can indeed beneficially impact mental health outcomes in these contexts. However, these reviews have tended to be narrowly focused, concentrating on specific (a) occupational contexts, (b) interventions, and/or (c) outcomes. With respect to occupational contexts, there are systematic reviews looking at specific occupations, like educators (e.g., Weare, 2014) or healthcare professionals (e.g., Lamothe et al., 2016). Conversely, regarding interventions, some reviews selectively analyse certain MBIs, mainly MBSR (e.g., Janssen et al., 2018). Finally, with outcomes, many reviews and meta-analyses are concerned with specific issues, such as depression (e.g., Tan et al., 2014) or psychological distress (e.g., Virgili, 2015).

As such, there is scope and need for more inclusive systematic reviews and metaanalyses with a more expansive remit with respect to occupational contexts, interventions, and outcomes. To that end, the present research team is conducting an ongoing, inclusive review of the literature on mindfulness in the workplace. This has already led to the publication of an overarching systematic review, featuring 153 papers and comprising 12,571 participants, focused on (a) all occupational contexts, (b) all forms of MBI, and (c) a range of wellbeing outcomes (Lomas et al., 2017a). This initiative has also produced two more narrowly-focused systematic reviews, looking at educators (Lomas et al., 2017b) and healthcare professionals (Lomas et al., 2018) specifically. There is real value in the kind of all-encompassing focus exhibited in the broadest review (Lomas et al., 2017a). First, in terms of occupational contexts, although it can be useful to focus on specific occupations - and healthcare professions are particularly well-represented in that respect, constituting over half $(n=82)$ of the studies analysed by Lomas et al. (2017a) - it is also relevant to explore the impact of MBIs across other occupational contexts. Unless that occurs, then studies which examine under-researched professions - which essentially means anything outside healthcare or education - will be overlooked by such reviews. Then, secondly, it is also worth looking at the diverse MBIs 
Running title: Mindfulness in the workplace

delivered in the workplace, rather than narrowly focusing on prominent interventions like MBSR. For instance, in our prior inclusive review, only $14 \%$ of interventions involved one of the two most established MBIs, MBSR (9\%) and MBCT (5\%). The remainder used either a bespoke MBSR adaptation (18\%), a less well-established MBI (29\%), of which there were 25 different types, or an idiosyncratic intervention or curriculum (39\%).

Finally, with respect to outcomes, there is value in having an expansive vision of which outcomes actually matter when considering the impact of MBIs, and accordingly being interested in a broad, inclusive set of outcomes. Most studies and reviews of MBIs - both in the workplace, and in other contexts too - tend to focus on negatively-framed "deficit-based" mental health outcomes such as anxiety or stress (i.e., whose absence is indicative of wellbeing). This is understandable, given the clinical contexts in which MBIs were initially implemented and developed. However, such outcomes only represent a partial reading of the broader notion of wellbeing. That is, the concept of "wellbeing" is increasingly used in academia as an overarching, multidimensional term, incorporating all the ways a person might hope to do or be well (de Chavez, Backett-Milburn, Parry, \& Platt, 2005), including physical health (Larson, 1999), cognitive performance (Tang et al., 2007), and positive affect (Diener, 2000). For instance, Pollard and Davidson (2001) define wellbeing as "a state of successful performance across the life course integrating physical, cognitive and social-emotional function" (p.10). Furthermore, wellbeing can be appraised not only in deficit-based negative terms, but also in asset-based positive terms. With the former, wellbeing consists in the absence of some undesirable quality or process, such as outcomes like anxiety, as noted above. However, that is not the whole story with respect to wellbeing. For instance, the emerging field of positive psychology was founded on the recognition that the absence of a deficit - i.e., being relatively free of mental health issues - does not necessarily entail the presence of an asset, i.e., that people are "flourishing." In that sense, the field has emphasised that we can (and should) 
Running title: Mindfulness in the workplace

also conceptualise wellbeing in asset-based positive terms, i.e., the presence of desirable qualities and processes, such as life satisfaction or meaning in life (Keyes, 2002). As such, our inclusive systematic review (Lomas et al., 2017a) was interested in both deficit-based wellbeing-related outcomes (e.g., stress) and asset-based ones (e.g., life satisfaction). Moreover, in that latter respect, the review was also interested in outcomes that could simply be regarded as associated with wellbeing - rather than directly being indices of it (e.g., as per life satisfaction) - such as emotional regulation and job performance. These outcomes are elucidated in more detail in the Methods section below, in which indicative definitions for the main outcomes are provided.

However, as valuable as our prior inclusive review may be, there are limits to the conclusions that can be drawn from a systematic review. To truly ascertain the impact of MBIs in occupational contexts, it is necessary to conduct a meta-analysis. As such, the current paper provides a meta-analysis of a small subset $(n=35)$ of the studies that were included in our previous inclusive systematic review $(n=153)$.

\section{Methods}

\section{Information Sources}

A literature search was performed using the MEDLINE and Scopus electronic databases by the first author in January 2016 (please see Lomas et al. (2017a) for details).

\section{Inclusion and Exclusion Criteria}

Included studies were randomised controlled trials examining the efficacy of MBIs in professional populations. A wide range of outcomes relating to wellbeing were examined, both negative deficit-based ones (e.g., anxiety, burnout, depression, and distress), and positive assetbased ones (e.g., life satisfaction), with the latter also including outcomes associated with wellbeing (e.g., compassion, emotional regulation, health, mindfulness, and resilience, as well as job performance). Exclusion criteria were theoretical articles, commentaries without 
Running title: Mindfulness in the workplace

statistical analyses, and pre-post or quasi-experimental empirical studies on MBIs. Studies were required to be published (or in press) in English in a peer-reviewed academic journal. The review was conducted according to the Preferred Reporting Items for Systematic Reviews and Meta-Analyses (PRISMA) guidelines (Moher, Liberati, Tetzlaff, \& Altman, 2009). The review protocol was registered with the International Prospective Register of Systematic Reviews (PROSPERO) database on $5^{\text {th }}$ January 2016 (registration number: CRD42016032899).

\section{Data Extraction}

The following variables were extracted from each paper by the second and fifth author: occupation of participants; size of the experimental sample; size of the control sample, and nature of the control condition; type and length of MBI; main wellbeing outcomes; and the mean and standard deviations of these main outcomes. The outcomes of interest included: (a) deficit-based wellbeing measures; (b) asset-based wellbeing measures. The deficit-based wellbeing measures were as follows (together with an indicative definition):

- Anxiety. State anxiety is defined in the State-Trait Anxiety Inventory (Spielberger, Gorsuch, \& Lushene, 1970) as "a transient momentary emotional status that results from situational stress," and trait anxiety as "a predisposition to react with anxiety in stressful situations." Generalised anxiety disorder is defined in the DSM-V (APA, 2013) according to six criteria, the first being "excessive anxiety and worry (apprehensive expectation), occurring more days than not for at least 6 months, about a number of events or activities (such as work or school performance)." (Please see DSM-V for the remaining criteria, and for other types of anxiety disorder.)

- Burnout. Defined by the Maslach Burnout Inventory (Maslach, Jackson, \& Leiter, 1986) as "a psychological syndrome of emotional exhaustion, depersonalization, and reduced personal accomplishment that can occur among individuals who work with other people in some capacity." 
Running title: Mindfulness in the workplace

- Depression. Defined by the WHO (2018) as "as a mood or mental disorder that causes a persistent feeling of sadness and loss of interest in pleasurable activities accompanied by an inability to carry out daily activities for at least 2 weeks." Major depressive disorder is defined in the DSM-V (APA, 2013) according to five criteria, the first being "five (or more) of the following symptoms have been present during the same 2-week period and represent a change from previous functioning; at least one of the symptoms is either (1) depressed mood or (2) loss of interest or pleasure." (Please see DSM-V for the remaining criteria and symptoms, and for other types of depressive disorder.)

- Distress. Defined generically as "unpleasant subjective stress responses such as anxiety and depression" (Matthews, 2016, p.219). In contrast to identified disorders, distress is more general in its definition and measurement, involving psychophysical and behavioural symptoms not specific to a given disorder, including anxious and depressive reactions.

- Stress. Defined by the Perceived Stress Scale (Cohen, 1986) as "the degree to which situations in one's life are appraised as stressful." Stressful in this context can be understood using Lazarus and Folkman's (1984) transactional model of stress, where it involves an imbalance between demands and resources, whereby individuals perceive that they cannot adequately cope with the demands being made on them.

Secondly, we looked at numerous asset-based wellbeing measures. These included "generic" measures of positive wellbeing, as commonly utilised in positive psychology, such as life satisfaction and positive affect. These also included outcomes associated with wellbeing (such as resilience) that were observed in the studies analysed. We were also interested in job performance (as a relevant metric regarding the impact of MBIs in occupational contexts). These outcomes were as follows (together with an indicative definition):

- Compassion/empathy. Compassion is defined by Neff (2003) as "being touched by the suffering of others, opening one's awareness to others' pain and not avoiding or 
Running title: Mindfulness in the workplace

disconnecting from it, so that feelings of kindness toward others and the desire to alleviate their suffering emerge" (pp.86-87). Relatedly, empathy can be defined as "an affective state that stems from the apprehension of another's emotional state or condition, and that is congruent with it" (Eisenberg \& Miller, 1987, p.91).

- Emotional regulation. Defined by Gross $(1998$, p.275) as the processes by which people "influence which emotions they have, when they have them, and how they experience and express these emotions."

- Job performance. Defined as "the total expected value to the organization of the discrete behavioural episodes that an individual carries out over a standard period of time" (Motowidlo, 2003, p.39). Outcomes of interest were usually specific to particular occupational contexts, such as the Caring Efficacy Scale in healthcare, and the Teachers' Sense of Efficacy Scale in education.

- Mindfulness has been influentially defined by Kabat-Zinn (2003, p.145) as "the awareness that arises through paying attention on purpose, in the present moment, and nonjudgmentally to the unfolding of experience moment by moment." This can be differentiated into trait and state forms, defined respectively as "the capacity for nonjudgmental, present-centered attention" and "the daily deviation from one's average daily level of mindfulness" (Eisenlohr-Moul, Peters, Pond, \& DeWall, 2016, p.718).

- Physical health. Health has been influentially defined by the WHO (1948) as "a state of complete physical, mental and social well-being, and not merely the absence of disease and infirmity." In the current paper, this kind of overarching, multidimensional state of wellness is labelled using the term "wellbeing." More narrowly, physical health could be defined as a "healthy organism capable of maintaining physiological fitness through protective or adaptive responses during changing circumstances" (Seymour, 2016, p.5). Outcomes of interest here include physical activity and sleep quality. 
Running title: Mindfulness in the workplace

- Positive wellbeing. The three main outcomes in this regard were life satisfaction, positive affect and resilience. Life satisfaction is defined within the context of the Satisfaction with Life Scale (Diener, Emmons, Larsen, \& Griffin, 1985) as “a global assessment of a person’s quality of life according to his chosen criteria" (Shin \& Johnson, 1978, p.478). Positive affect is defined within the context of the Positive and Negative Affect Scale (Watson, Clark, \& Tellegen, 1988) as a combination of pleasantness and high activation. Resilience can be defined as “the ability to 'bounce back' from adversity and go on with life" (Windle, 2011, p.155).

Whenever a study met all inclusion criteria to be included in the meta-analysis but did not report all the information needed to compute standardised mean differences, authors were contacted by the fourth author by email to request the missing data. Twelve authors did not reply to our queries, and so their studies were excluded from meta-analytic procedures.

\section{Quality Assessment}

The Quality Assessment Tool for Quantitative Studies (QATQS; National Collaborating Centre for Methods and Tools, 2008) was used to assess the quality of the studies (please see Lomas et al. (2017a) for details). Results of the scoring can be found in supplementary table 1.

\section{Statistical Analyses}

The meta package (Schwarzer, 2007) for the R software (R Core Team, 2017) was used to compute the statistical analyses and create plots. We assessed publication bias using contourenhanced funnel plots and Begg and Mazumdar (1994) tests by outcome valence. Due to heterogeneity in some outcomes, we used random effects models to calculate effect sizes. As most studies reported means and standard deviations and, according to the aforementioned variable grouping different scales were grouped under a common outcome type, we calculated standardized mean differences with 95\% confidence intervals for each outcome (Sedgwick \& Marston, 2013). When adding a negative valence scale to an asset-based outcome, means were 
Running title: Mindfulness in the workplace

recoded (multiplied by minus one) so that the valences coincided. For studies with more than one scale in the same outcome group, mean values for each of these metrics were converted to a single mean value for the intervention and control groups respectively. The variance of the mean among scales included within the same outcome grouping was calculated using Borenstein, Hedges, Higgins, and Rothstein's method (2009):

$$
\operatorname{var}\left(\frac{1}{m} \sum_{i=1}^{m} Y_{i}\right)=\left(\frac{1}{m}\right)^{2}\left(\sum_{i=1}^{m} V_{i}+\sum_{i \neq j}\left(r_{i j} \sqrt{V_{i}} \sqrt{V_{j}}\right)\right)
$$

When the correlation between scales was unknown, $r=.5$ was assumed as a midpoint between total independence and total dependence. Active control arms (John, Kumar, \& Lal, 2012; Malarkey, Jarjoura, \& Klatt, 2013; Shonin, Van Gordon, Dunn, Singh, \& Griffiths, 2014), were not considered for the weighted parameters. We consider this necessary to preserve the statistical independence of assumptions, controlling therefore the risk of bias due to the inflation of the overall effect size's variance. Heterogeneity was assessed for each sub-outcome using both the $\mathrm{Q}$ and the $\mathrm{I}^{2}$ statistics. For each outcome we calculated moderator analyses including MBSR (versus other interventions), the use of retreatments, region (North America versus the rest of the world), type of sample (students versus professionals), year of study, length of intervention, mean age of participants receiving the intervention, percentage of women receiving the intervention, and QATQS score as covariates.

\section{Results}

\section{Search Results}

The initial stages of the search procedure were undertaken as part of the prior inclusive systematic review (Lomas et al., 2017a), which included 153 papers. For that review, following removal of duplicate citations, 721 potentially relevant papers were retrieved. From the abstract review, 479 papers were excluded. From the full text review of the remaining 242 papers, 89 were excluded since they did not meet the inclusion and exclusion criteria of the initial review; 
Running title: Mindfulness in the workplace

these 153 papers were then included in the original systematic review. Then, for the current meta-analysis, a further 106 papers were excluded, as they did not meet the inclusion and exclusion criteria for the meta-analysis. Thus, a total of 47 articles providing results from RCTs fulfilling all eligibility criteria were found, but only 35 were able to be included in the metaanalysis (since we did not receive a response from authors to our data request for 12 articles). The PRISMA flow diagram shown in figure 1 outlines this selection process. The 47 articles comprised a total of 3,942 participants (discounting participants not included in the analyses due to attrition) - featuring roughly equal numbers of participants undertaking MBIs $(1,966)$ and separate control participants $(1,976)$ - reduced to 3,090 for the 35 studies in the metaanalysis. Seventy-four percent of the participants were women and the average age was 38.5 years. More than half of the studies (57.1\%) were carried out in North America (United States and/or Canada). A quarter had been carried out in Europe, and the remaining three studies were carried out in Colombia, India and Taiwan. The studies covered a range of occupations, including healthcare professionals $(n=13)$, teachers $(n=8)$, mixed employees (i.e., studies on workers "in general," not focused on a specific occupation or employment context; $n=5$ ), trainee healthcare professionals $(n=4)$, call-centre employees $(n=3)$, university employees $(n$ $=3$ ), factory employees $(n=2)$, social workers $(n=1)$, trainee social workers $(n=1)$, insurance company employees $(n=1)$, civil servants $(n=1)$, laboratory technicians $(n=1)$, office administrators $(n=1)$, professional athletes $(n=1)$, intellectual disability support staff $(n=1)$, and human service employees $(n=1)$. The vast majority of studies were based on psychometric scales. There were some exceptions. Roeser et al. (2013) and van Berkel et al. (2014a) included behavioural observations. Flook, Goldberg, Pinger, Bonus, and Davidson (2013), Harris, Jennings, Katz, Abenavoli, et al. (2016), Malarkey et al. (2013), Roeser et al. (2013), and Wolever et al. (2012) included biological markers of stress. Finally, Flook et al. (2013), John et al. (2012), and Roeser et al. (2013) included job performance measures. 
Running title: Mindfulness in the workplace

Figure 1. The Preferred Reporting Items of Systematic Reviews and Meta-Analyses

(PRISMA) Flow Diagram

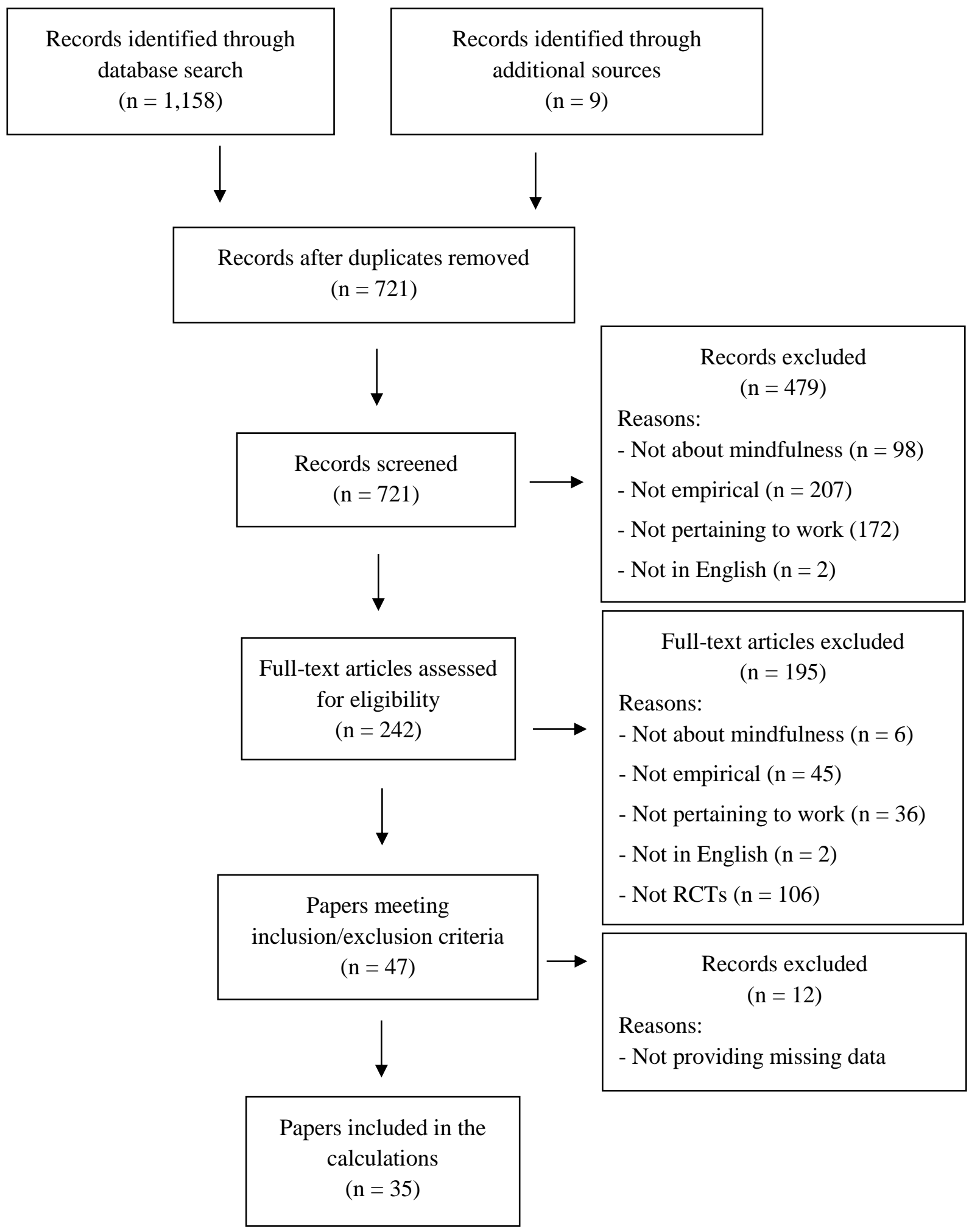


Running title: Mindfulness in the workplace

\section{Reporting Bias}

Two funnel plots were built, which grouped positive asset-based (e.g. life satisfaction) and negative deficit-based (e.g. depression) outcome measures separately (see figures 2 and 3). The first funnel plot, encompassing all asset-based outcome measures, indicated a relatively large group of outlier outcomes showing unusual increases (although also a few show unexpected reductions), suggesting a minor tendency to report effect sizes favouring MBI larger than expected. In the second, reporting deficit-based outcome measures, the number of outliers is smaller and the distribution seems more symmetric. Begg and Mazumdar's (1994) tests showed statistically significant asymmetry for positive $(z=2.11, p=.035)$ but not for negative $(z=-$ $0.91, p=0.36)$ outcomes.

Figure 2. Funnel plot of positive outcomes.

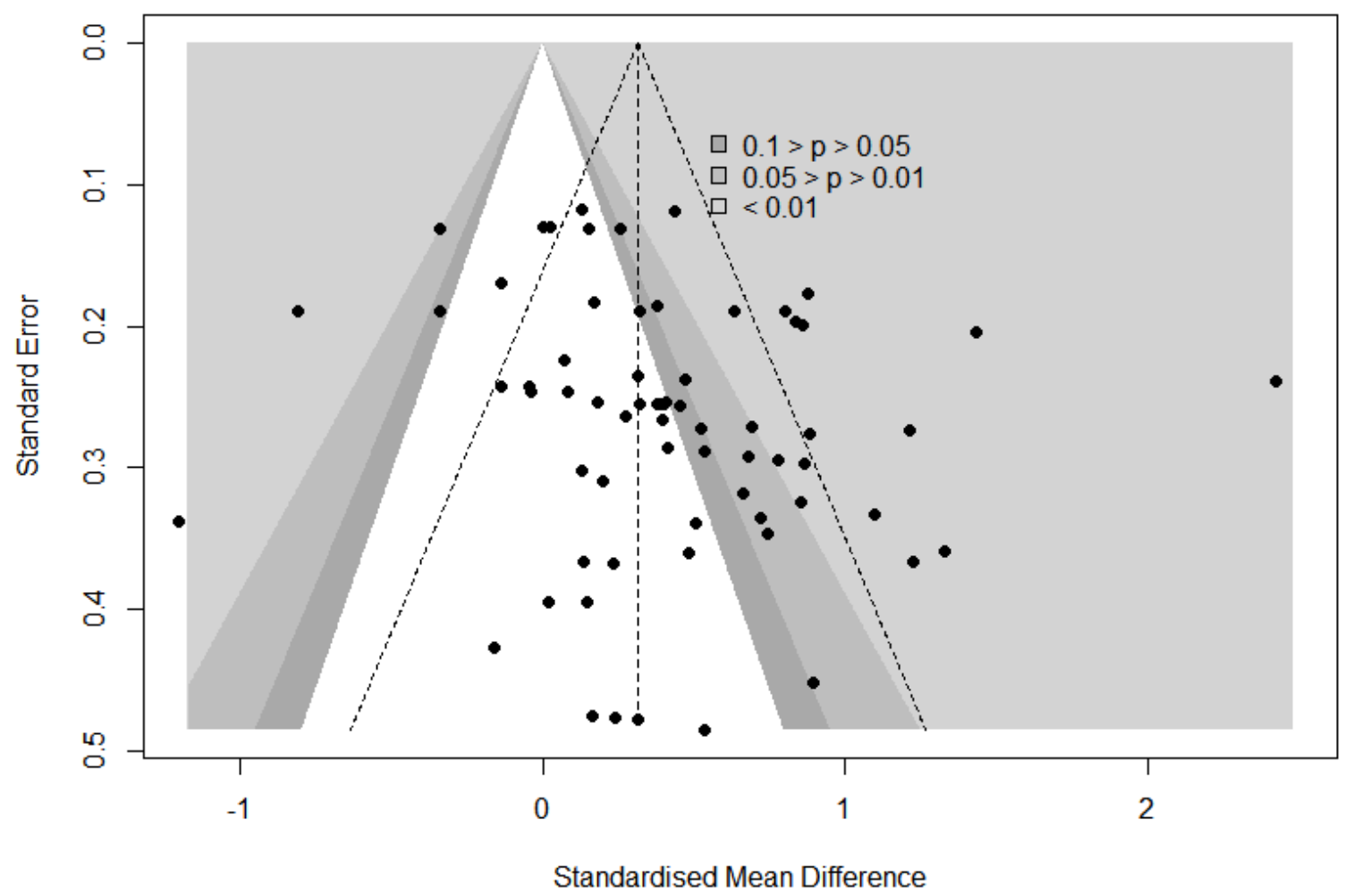

Figure 3. Funnel plot of negative outcomes. 


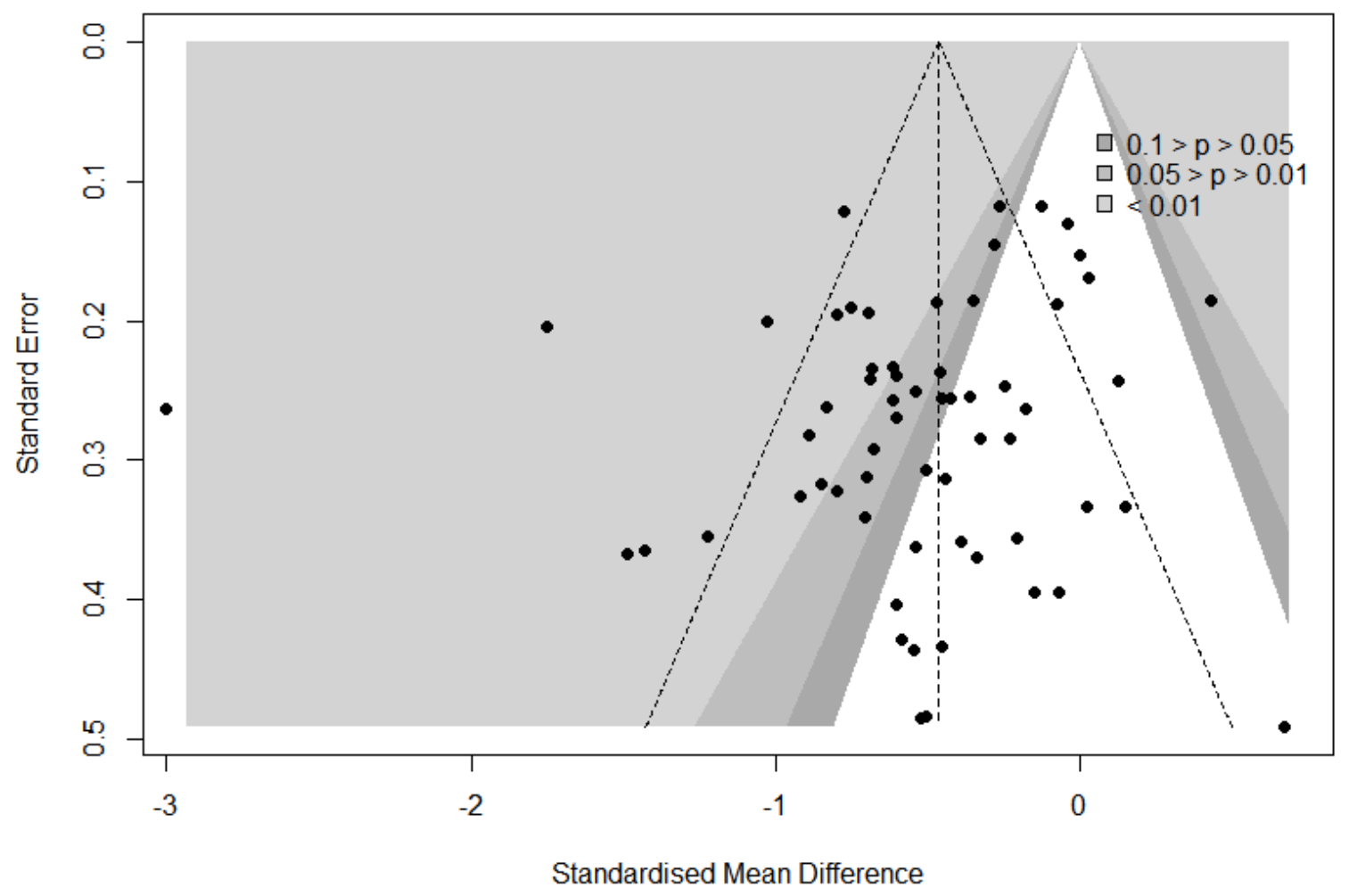

\section{Results by Outcome}

Table 1 shows a summary of metanalytic parameters by outcome group (forest plots and the database can be found as supplemental online material). As it can be seen in the table, statistically significant aggregated effect sizes (range: $-0.57-0.63$ ) were found for seven outcomes. Heterogeneity was statistically significant for six outcomes. Of note, some studies, such as Klatt et al. (2009) and Wolever et al. (2012), provided conflicting scores that could be considered outliers, namely mindfulness in the former and depression and emotional regulation in the latter. We carried out a detailed analysis of these studies and we saw that in both cases there were important differences in the baseline between the experimental and control groups. In addition, in the case of Wolever et al. (2012), a change in the expected direction (i.e. decrease in depression and increase in emotional regulation) occurred for both the control and the experimental groups. This is possibly a self-selection effect, since both courses offered a course 
Running title: Mindfulness in the workplace

to improve stress and probably attracted workers with relatively high baseline levels. In such cases, scores are usually subject to the effect of regression to the mean.

Statistically significant moderator effects were found for region regarding burnout $(Q=6.73$, $p=.01)$ and health $(Q=8.34, p=.004)$ with higher effect sizes for studies conducted in North America. The use of standardised MBSR versions (versus other interventions) predicted higher gains in health $(Q=4.36, p=.04)$. A higher proportion of women in the intervention group predicted higher gains in compassion $(Q M=5.97, p=.015)$ and positive wellbeing $(Q M=$ $3.85, p=.05)$. Higher QATQS scores predicted higher gains in compassion $(Q M=5.65, p=$ $.003)$, emotional regulation $(Q M=7.90, p=.005)$, health $(Q M=9.47, p=.019)$, and greater decreases in distress $(Q M=6.12, p=.013)$. Younger age predicted higher gains in health $(Q M$ $=3.89, p=.049)$. 
Running title: Mindfulness in the workplace

Table 1 . Summary of metanalytic parameters

\begin{tabular}{|c|c|c|c|c|c|c|c|c|c|}
\hline \multirow[b]{2}{*}{ Outcome } & \multirow[b]{2}{*}{$\begin{array}{l}\mathbf{N}^{0} \\
\text { studies }\end{array}$} & \multirow[b]{2}{*}{ Instruments } & \multirow[b]{2}{*}{$S M D$} & \multirow[b]{2}{*}{$95 \% C I$} & \multirow[b]{2}{*}{$z$} & \multirow[b]{2}{*}{$p$} & \multicolumn{3}{|c|}{ Heterogeneity } \\
\hline & & & & & & & $Q$ & $p$ & $12 \%$ \\
\hline Anxiety & 5 & $\begin{array}{l}\text { Depression Anxiety Stress Scale - Anxiety } \\
\text { Smith Anxiety Scale } \\
\text { State-Trait Anxiety Inventory } \\
\text { Symptom Checklist-90-R - Anxiety }\end{array}$ & -0.57 & $-0.81,-0.33$ & -4.71 & $<.0001$ & 1.51 & .824 & 0 \\
\hline Burnout & 14 & $\begin{array}{l}\text { Maslach Burnout Inventory } \\
\text { Questionnaire on the Experience and Evaluation of Work } \\
\text { Recovery Experience Questionnaire - Psychological detachment } \\
\text { Shirom-Melamed Burnout Measure } \\
\text { Shirom Vigor Scale }\end{array}$ & -0.36 & $-0.55,-0.16$ & -3.55 & .0004 & 31.99 & .0024 & 59.4 \\
\hline Compassion \& empathy & 8 & $\begin{array}{l}\text { Empathy Construct Rating Scale } \\
\text { Jefferson Scale of Physician Empathy } \\
\text { Santa Clara Brief Compassion Scale } \\
\text { Self-Compassion Scale } \\
\text { Tendency to Forgive scale }\end{array}$ & 0.42 & $0.21,0.71$ & 3.66 & .0002 & 11.84 & .1060 & 40.9 \\
\hline Depression & 6 & $\begin{array}{l}\text { Beck Depression Inventory } \\
\text { Center for Epidemiological Studies - Depression } \\
\text { Depression Anxiety and Stress Scales - Depression } \\
\text { Symptom Checklist-90-R - Depression }\end{array}$ & -0.48 & $-0.99,0.03$ & 1.86 & .0631 & 32.05 & $<.0001$ & 84.4 \\
\hline Distress \& anger & 14 & $\begin{array}{l}\text { Brief Symptom Inventory } \\
\text { Chinese Health Questionnaire } \\
\text { Distress Tolerance Scale } \\
\text { General Health Questionnaire } \\
\text { Profile of Mood States } \\
\text { Psychological Distress Manifestation Scale } \\
\text { Symptom Checklist-90-R - GSI }\end{array}$ & -0.56 & $-0.72,-0.41$ & -7.14 & $<.0001$ & 19.48 & .1090 & 33.3 \\
\hline Emotional regulation & 6 & $\begin{array}{l}\text { Affective Self -Regulatory Efficacy Scale } \\
\text { Difficulties in Emotion Regulation Scale - Impulse control } \\
\text { difficulties } \\
\text { Emotion Regulation Questionnaire } \\
\text { Teacher-Teacher Relational Trust }\end{array}$ & 0.28 & $-0.33,0.89$ & 0.89 & .373 & 33.68 & $<.0001$ & 85.2 \\
\hline Health & 9* & $\begin{array}{l}\text { Checklist Individual Strength Questionnaire } \\
\text { Daily Physical Symptoms Scale } \\
\text { Fatigue Scale } \\
\text { Physical activity (accelereometer) } \\
\text { PROMIS Sleep-Related Impairment Scale } \\
\text { PSQI } \\
\text { RAND-36 - Mental health items } \\
\text { Short Questionnaire to Assess Health Enhancing Physical Activity }\end{array}$ & 0.63 & $0.39,0.88$ & 5.15 & $<.0001$ & 21.19 & .0067 & 62.2 \\
\hline
\end{tabular}


Running title: Mindfulness in the workplace

\begin{tabular}{|c|c|c|c|c|c|c|c|c|c|}
\hline Job performance & 9 & $\begin{array}{l}\text { Absences from work } \\
\text { Caring Efficacy Scale } \\
\text { Classroom Assessment Scoring System - Classroom organisation } \\
\text { Job Content Questionnaire } \\
\text { Performance Score Test } \\
\text { Teachers' Sense of Efficacy Scale } \\
\text { Utrecht Work Engagement Scale } \\
\text { Work Limitations Questionnaire }\end{array}$ & 0.43 & $0.04,0.82$ & 2.16 & .0305 & 57.77 & $<.0001$ & 86.2 \\
\hline $\begin{array}{l}\text { Mindfulness \& } \\
\text { awareness }\end{array}$ & 20 & $\begin{array}{l}\text { Affective Go/No-Go task - Affective attentional bias } \\
\text { Cognitive and Affective Mindfulness Scale-Revised } \\
\text { Difficulties in Emotion Regulation Scale - Lack of emotional } \\
\text { awareness } \\
\text { Errors on math distractor problems } \\
\text { Five Facet Mindfulness Questionnaire } \\
\text { Heart Rate Coherence } \\
\text { Mindfulness Attention Awareness Scale } \\
\text { Operation span } \\
\text { Rapid Visual Information Processing task - Sustained attention } \\
\text { RR interval (time between heart beats) }\end{array}$ & 0.39 & $0.10,0.68$ & 2.61 & .0091 & $\begin{array}{l}132.1 \\
1\end{array}$ & $<.0001$ & 86.4 \\
\hline Stress \& strain & 23 & $\begin{array}{l}\text { Breathing rate } \\
\text { Classroom appraisal of resources and demands } \\
\text { Coping with Stress Questionnaire } \\
\text { Cortisol day's slope } \\
\text { Depression Anxiety and Stress Scale - Stress } \\
\text { Diastolic blood pressure } \\
\text { Heart Rate Coherence } \\
\text { Inflammatory peptide CRP } \\
\text { Interleukin } 6 \\
\text { Morning cortisol } \\
\text { Perceived Stress Scale } \\
\text { Perceived Medical School Stress } \\
\text { Psychological Stress Measure } \\
\text { Systolic blood pressure } \\
\text { Time urgency scale } \\
\text { Work-Related Stress Indicator Tool }\end{array}$ & -0.60 & $-0.89,-0.31$ & -4.07 & .0001 & $\begin{array}{l}174.9 \\
9\end{array}$ & .0001 & 87.9 \\
\hline
\end{tabular}




\section{Running title: Mindfulness in the workplace}

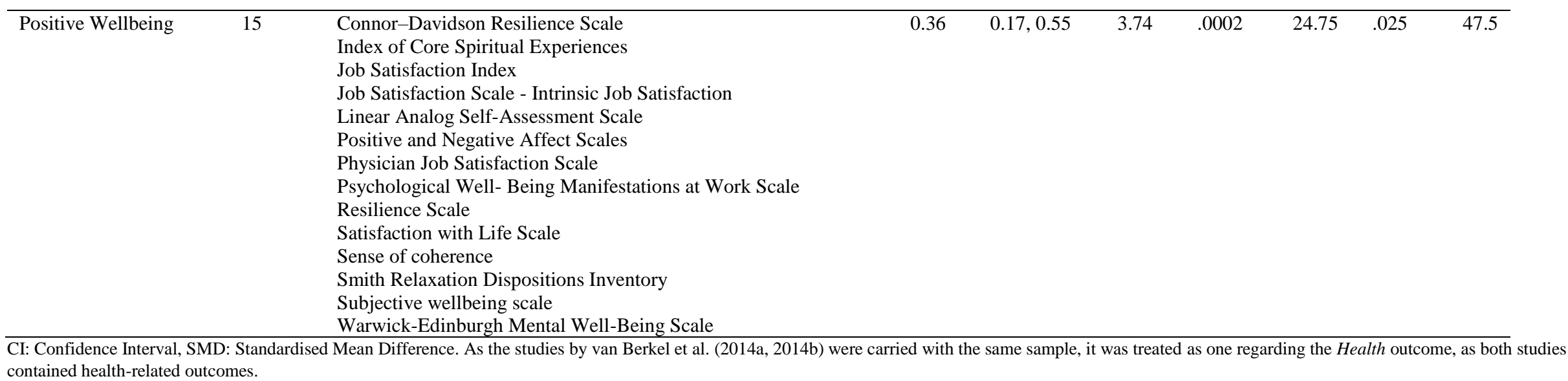


Running title: Mindfulness in the workplace

\section{Discussion}

Overall, MBIs had a positive impact upon most outcome measures. However, there was considerable heterogeneity and variation in the strength of the effect. The strongest outcomes were with respect to health $(S M D$ [standardized mean difference] $=0.63)$, stress $(S M D=-0.57)$, anxiety $(S M D=-0.57)$ and distress $(S M D=-0.56)$. (Although heterogeneity was statistically significant in the case of health, we can consider these solid results, since in no case did the control group have better scores than the intervention group.) These findings corroborate and indeed strengthen the result of Virgili's (2013) meta-analysis of the impact of 19 MBIs on psychological distress in the workplace, which observed a medium-to-large effect size. Given the heavy and widespread burden of occupational stress, as noted in the introduction, such figures are welcome. As reported above, the Fifth European Working Conditions Survey (Eurofound, 2012) found that $22 \%$ of European workers reported experiencing work-related stress, with many more exposed to the psychosocial risks of such stress. Moreover, in specific national and occupational contexts, levels of work-related stress may be far higher than $22 \%$. For instance, in a recent survey of over 3,700 public sector workers in the UK, $61 \%$ of staff surveyed who worked for the NHS reported feeling stressed all or most of the time, and 59\% stated that the stress was currently worse than the previous year (Dudman, Isaac, \& Johnson, 2015). In that context, if initiatives like MBIs can help ameliorate these burdens, that is encouraging news. Needless to say, that does not preclude organisations also working to fix the structural causes of stress, such as heavy workload and time pressures.

More moderate findings - small to medium effect sizes - were observed with respect to depression $(S M D=-0.48)$, which did not reach statistical significance, and burnout $(S M D=$ $-0.36)$, as well as positive outcomes such as job performance $(S M D=0.43)$, compassion and empathy $(S M D=0.42)$, mindfulness $(S M D=0.39)$ and positive wellbeing $(0.36)$. In all but the 
Running title: Mindfulness in the workplace

case of compassion and empathy, statistically significant heterogeneity was found. Again, these findings are somewhat encouraging, albeit not wholly convincing. With depression, in addition to the debilitation of those unable to work due to the condition, there may also be high levels of depression among those in work. In relation to GPs in the UK, for instance, Caplan (1994) reported that $27 \%$ were on the limit or likely to be depressed, while Firth-Cozens (1998) found that $16.8 \%$ were above the threshold on the depression scale of the Symptom Checklist 90 . By contrast, among the general UK adult population, around $2.3 \%$ are estimated to experience a depressive episode at any one time, with $9 \%$ experiencing mixed anxiety and depressive disorder (The Health and Social Care Information Centre, 2009). There are many hypothesised reasons for this liability to depression among those in professions such as healthcare, including personality traits such as self-criticism and perfectionism, burdens of clinical responsibility, and workload (Bright \& Krahn, 2011). Whatever the causes, it is encouraging that some MBIs appear to help in this regard, reflecting the more established efficacy of MBIs such as MBCT with respect to depression (Segal et al., 2002). In this regard, our review augments the findings of Tan et al. (2014), whose meta-analysis of nine RCTs of interventions aimed at ameliorating depression in the workplace - including but not limited to MBIs - observed a small positive effect. However, as noted above, here the effect size for depression did not reach statistical significance. This is possibly a reflection of the more general trend in the mindfulness literature that while MBIs such as MBCT can help prevent relapse of depression (Ma \& Teasdale, 2004), its efficacy with respect to current depression less well-established (and in fact MBIs are often contraindicated in such contexts; van Dam et al., 2018).

The smaller effect sizes for mindfulness, burnout, and job performance are also intriguing. It is perhaps relevant that these outcomes all registered significant heterogeneity and subgroup differences, as did the analyses for distress and depression. Relatedly, it may be further relevant that these are not unitary constructs but can be construed in different ways. For 
Running title: Mindfulness in the workplace

instance, with mindfulness, the two most popular tools used in occupational settings (and indeed more generally) are Brown and Ryan's (2003) 15-item Mindful Attention and Awareness Scale (MAAS), and Baer, Smith, Hopkins, Krietemeyer, and Toney’s (2006) 39item Five Facets of Mindfulness Scale FFMQ). The MAAS focuses on a single, core characteristic of mindfulness, namely open and receptive awareness, which to an extent aligns with Kabat-Zinn's (2003) definition cited above (although the scale has been critiqued for omitting the non-judgmental/acceptance part of mindfulness, which many regard as an essential component of mindfulness; van Dam, Sheppard, Forsyth, \& Earleywine, 2011). By contrast, the FFMQ involves five dimensions: describing, acting with awareness, non-judging of inner experience, and non-reactivity to inner experience. It is conceivable that MBIs may differentially impact certain components or aspects of mindfulness more than others; as such, aggregating disparate measures together in meta-analyses may dilute the observed effect of MBIs on specific aspects of mindfulness. Similarly, with burnout, the dominant measure is the Maslach Burnout Inventory (Maslach, Jackson, \& Leiter, 1986), which has three dimensions: emotional exhaustion, cynicism (or depersonalisation), and professional efficacy (or accomplishment). When considering the components separately, several studies found that MBIs tended to have a stronger positive effect on emotional exhaustion compared to the other two components. On that note, it may be relevant that Demerouti and Bakker (2008) argue that personal efficacy/accomplishment should not be regarded as a core component of burnout, but rather as simply one of its outcomes. It is therefore possible that the presence of this factor in the Maslach Burnout Inventory may be diluting the impact of the MBIs, and that other measures of burnout which exclude the factor, such as the Oldenburg Burnout Inventory (Demerouti \& Bakker, 2008), might prove to be more precisely-targeted in this respect.

Finally, a small and non-statistically significant effect was observed with respect to emotional regulation $(S M D=0.28)$. The modest nature of this result is somewhat surprising, 
Running title: Mindfulness in the workplace

given that MBIs are theorised to directly impact upon such capacities, which in turn is thought to account for the generally beneficial outcomes adumbrated above. For instance, in their systematic review of the impact of MBSR on "emotional competencies" in healthcare professionals, Lamothe et al. (2016) found that training to "better regulate one's emotions" played a key role in improving wellbeing-related outcomes (both deficit- and asset-based) (p.19). As outlined in the introduction, a key mechanism through which mindfulness is theorised to exert its positive effects is "reperceiving" (Shapiro et al., 2006), also known as decentring (Fresco et al., 2007), which can be regarded as an aspect of a more general capacity of emotion regulation. For instance, Walsh and Shapiro (2006) define meditation as "a family of self-regulation practices that focus on training attention and awareness in order to bring mental processes under greater voluntary control and thereby foster general mental well-being" (pp.228-229). Thus, a common theoretical position is that mindfulness may enhance mental health in the following way: (a) mindfulness involves introspective practices that enhance attention and awareness; (b) their development improves emotional regulation (including abilities such as reperceiving); and (c) emotional regulation is a meta-skill that subserves multiple wellbeing outcomes (Aldao et al., 2010). However, as noted, we found only a small and non-significant relationship between MBIs and emotional regulation. Future work is clearly needed to elucidate these hypothesised causal chains further (e.g., through longitudinal studies deploying regression analyses), to establish the extent to which capacities such as emotional regulation really are key mechanisms in accounting for the efficacy of MBIs.

Finally, It should be noted that the results were moderated by several variables. More significant results (i.e., a greater reduction in negative outcomes and/or increase in positive outcomes) were produced by studies: (a) with a higher quality design (vis-à-vis compassion, emotional regulation, distress, and health); (b) using the original MBSR protocol (vis-à-vis health); (c) conducted in North America (vis-à-vis burnout and health); (d) with a higher 
Running title: Mindfulness in the workplace

proportion of women in the intervention group (vis-à-vis compassion and positive wellbeing); and/or (e) with younger participants (vis-à-vis health). The first variable is perhaps to be expected: it is a reasonable conjecture that studies which are well-designed and reported-on (from a methodological perspective) would also be well-run and facilitated (from a participant perspective), with good quality mindfulness teaching and support, thus enhancing the learning experience of participants (see Davidson and Kaszniak (2015) for commentary on this topic). Similar considerations possible apply to the second factor (type of MBI), in that since MBSR is the most well-established and -tested MBI, such courses may tend to have a better participant experience, and teach mindfulness more effectively. Regarding the third factor, the impact of region, here cultural considerations come into play. It is conceivable that, although mindfulness is based on teachings and practices originating in the Indian subcontinent, its operationalisation in contemporary psychology has been influenced by the mainly North American context in which it was harnessed and developed by the likes of Jon Kabat-Zinn (Lomas, 2017). As such, the way in which teachings have been formulated and presented in MBIs like MBSR potentially holds more appeal and familiarity to participants who are also from this North American context (Wilson, 2014). Regarding the fourth factor (more women in the intervention group), researchers are beginning to look at mindfulness through the prism of gender (see e.g., Lomas et al., 2013, 2014, 2015, 2016), drawing on literature which suggests men may have more difficulty than women in engaging with their emotions (e.g., due to the socialisation of masculinity norms such as invulnerability and stoicism) (Courtenay, 2000). In that light, it is understandable that females may be relatively more responsive to developing qualities such as compassion through meditation then men. Finally, the association between younger age and greater gains in health possibly relates to the notion that patterns of behaviour (e.g., sleep, exercise) are more malleable in the young, and so are more subject to influence (Breinbauer \& Maddaleno, 2005). 
Running title: Mindfulness in the workplace

Overall though, MBIs had a generally positive impact upon most measures. Moreover, a fairly large evidence-base regarding the use of mindfulness in workplace settings is gradually accumulating. Together, these studies suggest that mindfulness can potentially reduce mental health issues (e.g., stress), enhance wellbeing-related outcomes (e.g., emotional regulation), and improve aspects of job performance. However, there are numerous issues with both the research base and our analysis of it which limit the conclusions that can be drawn. First, studies are of variable quality. Using the QATQS scoring method, few studies scored highly in all respects. For instance, most studies did not give sufficient details about their design (e.g., the precise nature of the MBI). Second, there is considerable heterogeneity in these designs including with respect to the type of MBI, and outcome measures used - which makes it difficult to draw meaningful conclusions about the research as a whole. Third, most studies failed to deploy any kind of active control group - i.e., a non-MBI intervention that might conceivably also be beneficial, such as exercise - which makes it difficult to determine the extent to which any positive results are due to mindfulness per se (a conclusion also reached by Virgili (2013) in his meta-analysis). Fourth, the research is currently biased towards certain occupations, outcome measures, and MBIs. Studies are heavily weighted towards healthcare professionals, with a distinct paucity of research regarding most other kinds of occupations/workplaces. Then, research predominantly assesses negative deficit-based mental health outcomes, with little attention to other outcomes relevant to the work arena, such as work engagement or creativity. Fifth, the majority of studies focused on MBSR (or idiosyncratic adaptions of this); there is little research into other MBIs, particularly MBIs developed specifically for the workplace. Finally, when it comes to reporting the results, our funnel plots showed a minor tendency to report effect sizes favouring MBIs both for negative and positive outcomes, which indicates a bias towards not publishing negative results. 
Running title: Mindfulness in the workplace

There are also limitations to our review itself. To begin with, despite our efforts towards inclusivity, it is likely that our search strategy did not capture all the research on MBIs in the workplace that existed at the time the search was conducted (in early 2016). For a start, we only looked at peer-reviewed journal articles published in English that were in the MEDLINE and Scopus databases, which excludes any articles not meeting those criteria. Moreover, we did not examine the undoubtedly large "grey" (i.e., unpublished) literature that inevitably exists, such as trials conducted by organisations that have not been written-up and submitted to journals, and papers which have been written by academics but not published. This latter in particular is an issue in terms of the "file-drawer" problem (negative or non-significant results being less likely to be published; Franco, Malhotra, \& Simonovits, 2014).

Based on the critiques above, some recommendations can be made concerning future work in this area. First, there would ideally be a diversification of occupations/workplaces examined, particularly non-healthcare-related occupations. Second, it would also be good to see a diversification of outcome measures, with a greater number of studies looking beyond negative psychiatric issues (e.g., anxiety) to also focus on more positive outcomes, such as emotional regulation and life satisfaction. Likewise, there is considerable scope for studies to examine metrics which were not observed in any of the studies analysed here but which are nevertheless relevant to wellbeing and performance in the workplace, such as creativity (see Kudesia, 2015, for reflections on the potential links between mindfulness and creativity in the workplace). Third, in addition to the standard wait-list control group, it would be useful to include an active control group (e.g., an exercise programme). This will better enable any positive effects to be ascribed to mindfulness per se (i.e., rather than simply being involved in an absorbing activity). Fourth, where possible, trials should involve established MBIs (i.e., rather than bespoke adaptations), to better enable comparison and aggregation across studies. However, these is also a need to move beyond MBIs that were developed for clinical contexts 
Running title: Mindfulness in the workplace

(e.g., MBSR), and to explore MBIs created specifically for the workplace. Finally, research would do well to enquire into the moderator effects observed here, as outlined above (i.e., the impact of factors such as study quality, type of MBI, region, gender, and age). Nevertheless, despite the issues with the current research base, the evidence of the value of mindfulness in the workplace remains strong, and one might well speculate that this will only strengthen over the years ahead.

\section{Disclosure statement}

No potential conflict of interest was reported by the authors.

\section{Funding}

Dr. Eiroa-Orosa has received funding from the European Union's Framework Programme for Research and Innovation Horizon 2020 (2014-2020) under the Marie Sklodowska-Curie Grant Agreement No 654808 .

\section{ORCID}

Tim Lomas http://orcid.org/0000-0001-9458-6185

Joan Carles Medina http://orcid.org/0000-0002-4550-2157

Francisco José Eiroa-Orosa http://orcid.org/0000-0002-4163-6545

\section{References}

* Aikens, K. A., Astin, J., Pelletier, K. R., Levanovich, K., Baase, C. M., Park, Y. Y., \& Bodnar, C. M. (2014). Mindfulness goes to work: Impact of an online workplace intervention. Journal of Occupational and Environmental Medicine, 56(7), 721-731. doi: 10.1097/jom.0000000000000209

Aldao, A., Nolen-Hoeksema, S., \& Schweizer, S. (2010). Emotion-regulation strategies across psychopathology: A meta-analytic review. Clinical Psychology Review, 30(2), 217237. doi: 10.1016/j.cpr.2009.11.004 
Running title: Mindfulness in the workplace

American Psychiatric Association (2013). Diagnostic and Statistical Manual of Mental Disorders (Fifth ed.). Washington, DC: American Psychiatric Association.

Baer, R. A., Smith, G. T., Hopkins, J., Krietemeyer, J., \& Toney, L. (2006). Using self-report assessment methods to explore facets of mindfulness. Assessment, 13(1), 27-45. doi: $10.1177 / 1073191105283504$

Begg, C.B., \& Mazumdar, M. (1994). Operating characteristics of a rank correlation test for publication bias. Biometrics 50(4), 1088-1101. http://dx.doi.org/10.2307/2533446.

Borenstein, M., Hedges, L. V., Higgins, J. P. T., \& Rothstein, H. R. (2009). Multiple Outcomes or Time-Points within a Study. In Introduction to Meta-Analysis (pp. 225-238). Chichester, UK: John Wiley \& $\quad$ Sons, Ltd. https://doi.org/10.1002/9780470743386.ch24

Bourdieu, P. (1986). The forms of capital. In J. G. Richardson (Ed.), Handbook of Theory and Research for the Sociology of Education (pp. 241-258). New York: Greenwood.

Breinbauer, C., \& Maddaleno, M. (2005). Youth: Choices and change: Promoting healthy behaviors in adolescents. Washington DC: Pan American Health Organization.

Bright, R. P., \& Krahn, L. (2011). Depression and suicide among physicians. Current Psychiatry, 10(4), 16.

Brown, K. W., \& Ryan, R. M. (2003). The benefits of being present: Mindfulness and its role in psychological well-being. Journal of Personality and Social Psychology, 84(4), 822848. doi: 10.1037/0022-3514.84.4.822

* Burnett, M., \& Pettijohn, C. (2015). Investigating the efficacy of mind-body therapies and emotional intelligence on worker stress in an organizational setting: An experimental approach. Journal of Organizational Culture, Communications and Conflict, 19(1), $146-158$. 
Running title: Mindfulness in the workplace

Caplan, R. P. (1994). Stress, anxiety, and depression in hospital consultants, general practitioners, and senior health service managers. BMJ, 309(6964), 1261-1263. doi: $10.1136 / \mathrm{bmj} .309 .6964 .1261$

Chambers, R., Gullone, E., \& Allen, N. B. (2009). Mindful emotion regulation: An integrative review. Clinical Psychology Review, 29(6), 560-572. doi: 10.1016/j.cpr.2009.06.005

Chiesa, A., \& Serretti, A. (2009). Mindfulness-based stress reduction for stress management in healthy people: A review and meta-analysis. The Journal of Alternative and Complementary Medicine, 15(5), 593-600. doi: 10.1089=acm.2008.0495

Cohen, S. (1986). Contrasting the Hassles Scale and the Perceived Stress Scale: Who's really measuring appraised stress? American Psychologist,, 41(6), 716-718. doi: 10.1037/0003-066X.41.6.716

Courtenay, W. H. (2000). Constructions of masculinity and their influence on men's wellbeing: A theory of gender and health. Social Science \& Medicine, 50(10), 1385-1401. doi: 10.1016/S0277-9536(99)00390-1

Davidson, R. J., \& Kaszniak, A. W. (2015). Conceptual and methodological issues in research on mindfulness and meditation. American Psychologist, 70(7), 581-592.

Davies, S. (2014). Annual Report of the Chief Medical Officer 2013, Public Mental Health Priorities: Investing in the Evidence. London: Department of Health.

de Chavez, A. C., Backett-Milburn, K., Parry, O., \& Platt, S. (2005). Understanding and researching wellbeing: Its usage in different disciplines and potential for health research and health promotion. Health Education Journal, 64(1), 70-87. doi: $10.1177 / 001789690506400108$

* De Vibe, M., Solhaug, I., Tyssen, R., Friborg, O., Rosenvinge, J. H., Sørlie, T., \& Bjørndal, A. (2013). Mindfulness training for stress management: A randomised controlled study 
Running title: Mindfulness in the workplace

of medical and psychology students. BMC Medical Education, 13(1). doi: $10.1186 / 1472-6920-13-107$

Demerouti, E., \& Bakker, A. B. (2008). The Oldenburg Burnout Inventory: A good alternative to measure burnout and engagement. In J. R. B. Halbesleben (Ed.), Handbook of Stress and Burnout in Health Care. Hauppauge, NY: Nova Science.

Diener, E. (2000). Subjective well-being: The science of happiness and a proposal for a national index. American Psychologist, 55(1), 34-43. doi: 10.1037/0003-066X.55.1.34

Diener, E., Emmons, R. A., Larsen, R. J., \& Griffin, S. (1985). The satisfaction with life scale. Journal of Personality Assessment, 49(1), 71-75. doi: 10.1207/s15327752jpa4901_13

Dudman, J., Isaac, A., \& Johnson, S. (2015, 10 June 2015). Revealed: How the stress of working in public services is taking its toll on staff, The Guardian. Retrieved from http://www.theguardian.com/society/2015/jun/10/stress-working-public-servicessurvey

Eisenberg, N., \& Miller, P. A. (1987). Empathy, sympathy, and altruism: Empirical and conceptual links. In N. Eisenberg \& J. Strayer (Eds.), Empathy and its Development (pp. 292-316). Cambridge: Cambridge University Press.

Eisenlohr-Moul, T. A., Peters, J. R., Pond, R. S., \& DeWall, C. N. (2016). Both trait and state mindfulness predict lower aggressiveness via anger rumination: A multilevel mediation analysis. Mindfulness, 7(3), 713-726. doi: 10.1007/s12671-016-0508-x

* Erogul, M., Singer, G., McIntyre, T., \& Stefanov, D. G. (2014). Abridged Mindfulness Intervention to Support Wellness in First-Year Medical Students. Teaching and Learning in Medicine, 26(4), 350-356. doi: 10.1080/10401334.2014.945025

EU-OSHA - European Agency for Safety and Health at Work (2014). Calculating the cost of work-related stress and psychosocial risks. Publications Office of the European Union: Luxembourg. Available at: https://osha.europa.eu/en/tools- 
Running title: Mindfulness in the workplace

andpublications/publications/literature_reviews/calculating-the-cost-of-workrelatedstress-and-psychosocial-risks

Eurofound - European Foundation for the Improvement of Living and Working Conditions (2012). Fifth European working conditions survey. Publications Office of the European Union: Luxembourg. Available at: http://www.eurofound.europa.eu/surveys/ewcs/2010/

Firth-Cozens, J. (1998). Individual and organizational predictors of depression in general practitioners. British Journal of General Practice, 48(435), 1647-1651.

* Flaxman, P. E., \& Bond, F. W. (2010). Worksite stress management training: Moderated effects and clinical significance. Journal of Occupational Health Psychology, 15(4), 347-358. doi: 10.1037/a0020522

* Flook, L., Goldberg, S. B., Pinger, L., Bonus, K., \& Davidson, R. J. (2013). Mindfulness for teachers: A pilot study to assess effects on stress, burnout, and teaching efficacy. Mind, Brain, and Education, 7(3), 182-195. doi: 10.1111/mbe.12026

Franco, A., Malhotra, N., \& Simonovits, G. (2014). Publication bias in the social sciences: Unlocking the file drawer. Science, 345(6203), 1502-1505. doi: 10.1126/science. 1255484

* Frank, J. L., Reibel, D., Broderick, P., Cantrell, T., \& Metz, S. (2015). The effectiveness of Mindfulness-Based Stress Reduction on educator stress and well-being: Results from a pilot study. Mindfulness, 6(2), 208-216. doi: 10.1007/s12671-013-0246-2

Fresco, D. M., Moore, M. T., van Dulmen, M. H. M., Segal, Z. V., Ma, S. H., Teasdale, J. D., \& Williams, J. M. G. (2007). Initial psychometric properties of the experiences questionnaire: Validation of a self-report measure of decentering. Behavior Therapy, 38(3), 234-246. doi: 10.1016/j.beth.2006.08.003 
Running title: Mindfulness in the workplace

George, D. R., Dellasega, C., Whitehead, M. M., \& Bordon, A. (2013). Facebook-based stress management resources for first-year medical students: A multi-method evaluation. Computers in Human Behavior, 29(3), 559-562. doi: 10.1016/j.chb.2012.12.008

Goh, J., Pfeffer, J., \& Zenios, S. A. (2015). The relationship between workplace stressors and mortality and health costs in the United States. Management Science, 62(2), 608-628. doi: $10.1287 / \mathrm{mnsc} .2014 .2115$

* Grégoire, S., \& Lachance, L. (2015). Evaluation of a Brief Mindfulness-Based Intervention to Reduce Psychological Distress in the Workplace. Mindfulness, 6(4), 836-847. doi: $10.1007 / \mathrm{s} 12671-014-0328-9$

* Grégoire, S., Lachance, L., \& Taylor, G. (2015). Mindfulness, mental health and emotion regulation among workers. International Journal of Wellbeing, 5(4).

Gross, J. J. (1998). The emerging field of emotion regulation: An integrative review. Review of General Psychology, 2(3), 271-299.

* Harris, A. R., Jennings, P. A., Katz, D. A., Abenavoli, R. M., \& Greenberg, M. T. (2015). Promoting Stress Management and Wellbeing in Educators: Feasibility and Efficacy of a School-Based Yoga and Mindfulness Intervention. Mindfulness, 7(1), 143-154. doi: $10.1007 / \mathrm{s} 12671-015-0451-2$

Hassard, J., Teoh, K. R. H., Visockaite, G., Dewe, P., \& Cox, T. (2018). The cost of workrelated stress to society: A systematic review. Journal of Occupational Health Psychology, 23(1), 1-17. doi: 10.1037/ocp0000069

Health and Safety Executive (2016). Work related Stress, Anxiety and Depression Statistics in Great Britain 2016. London: Health and Safety Executive.

* Huang, S. L., Li, R. H., Huang, F. Y., \& Tang, F. C. (2015). The potential for mindfulnessbased intervention in workplace mental health promotion: Results of a randomized controlled trial. PLoS One, 10(9). doi: 10.1371/journal.pone.0138089 
Running title: Mindfulness in the workplace

* Hülsheger, U. R., Alberts, H. J. E. M., Feinholdt, A., \& Lang, J. W. B. (2013). Benefits of mindfulness at work: The role of mindfulness in emotion regulation, emotional exhaustion, and job satisfaction. Journal of Applied Psychology, 98(2), 310-325. doi: $10.1037 / \mathrm{a} 0031313$

* Hülsheger, U. R., Feinholdt, A., \& Nübold, A. (2015). A low-dose mindfulness intervention and recovery from work: Effects on psychological detachment, sleep quality, and sleep duration. Journal of occupational and organizational psychology, 88(3), 464-489. doi: 10.1111/joop. 12115

Janssen, M., Heerkens, Y., Kuijer, W., Van Der Heijden, B., \& Engels, J. (2018). Effects of Mindfulness-Based Stress Reduction on employees' mental health: A systematic review. PLoS One, 13(1), e0191332.

* Jennings, P. A., Frank, J. L., Snowberg, K. E., Coccia, M. A., \& Greenberg, M. T. (2013). Improving classroom learning environments by cultivating awareness and resilience in education (CARE): Results of a randomized controlled trial. School Psychology Quarterly, 28(4), 374-390. doi: 10.1037/spq0000035

John, K. S., Kumar, V. S., \& Lal, K. G. (2012). The effect of music therapy and meditation on sports performance in professional shooters. International Journal of Research in Ayurveda and Pharmacy, 3(1), 133-136.

Kabat-Zinn, J. (1982). An outpatient program in behavioral medicine for chronic pain patients based on the practice of mindfulness meditation: Theoretical considerations and preliminary results. General Hospital Psychiatry, 4(1), 33-47. doi: 10.1016/01638343(82)90026-3

Kabat-Zinn, J. (2003). Mindfulness-based interventions in context: Past, present, and future. Clinical Psychology: Science and Practice, 10(2), 144-156. doi: 10.1093/clipsy.bpg016 
Running title: Mindfulness in the workplace

Keyes, C. L. M. (2002). The mental health continuum: From languishing to flourishing in life. Journal of Health and Social Behavior, 43(2), 207-222. doi: 10.2307/3090197

* Klatt, M. D., Buckworth, J., \& Malarkey, W. B. (2009). Effects of low-dose mindfulnessbased stress reduction (MBSR-ld) on working adults. Health Education and Behavior, 36(3), 601-614. doi: 10.1177/1090198108317627

Kudesia, R. S. (2015). Mindfulness and creativity in the workplace. In J. Reb \& P. W. B. Atkins (Eds.), Mindfulness in Organizations: Foundations, Research, and Applications (pp. 190-212). Cambridge: Cambridge University Press.

Lamothe, M., Rondeau, É., Malboeuf-Hurtubise, C., Duval, M., \& Sultan, S. Outcomes of MBSR or MBSR-based interventions in health care providers: A systematic review with a focus on empathy and emotional competencies. Complementary Therapies in Medicine, 24, 19-28. doi: 10.1016/j.ctim.2015.11.001

Lang, F. R. (2004). Social motivation across the life span. In F. R. Lang \& K. L. Fingerman (Eds.), Growing together: Personal relationships across the lifespan (pp. 341-367). Cambridge: Cambridge University Press.

Lomas, T. (2017). Recontextualising mindfulness: Theravada Buddhist perspectives on the ethical and spiritual dimensions of awareness. Psychology of Religion and Spirituality, Vol 9(2), 209-219. doi: 10.1037/rel0000080

Lomas, T., Cartwright, T., Edginton, T., \& Ridge, D. (2013). 'I was so done in that I just recognized it very plainly, "You need to do something"': Men's narratives of struggle, distress and turning to meditation. Health:, 17(2), 191-208. doi: $10.1177 / 1363459312451178$

Lomas, T., Cartwright, T., Edginton, T., \& Ridge, D. (2014). A religion of wellbeing?: The appeal of Buddhism to men in London, UK. Psychology of Religion and Spirituality, 6(3), 198-207. doi: 10.1037/a0036420 
Running title: Mindfulness in the workplace

Lomas, T., Cartwright, T., Edginton, T., \& Ridge, D. (2015). A qualitative analysis of experiential challenges associated with meditation practice. Mindfulness, 6(4), 848860. doi: 10.1007/s 12671-014-0329-8

Lomas, T., Cartwright, T., Edginton, T., \& Ridge, D. (2016). New ways of being a man: 'Positive' hegemonic masculinity in meditation-based communities of practice. Men and Masculinities, 19(3), 289-310. doi: 10.1177/1097184X15578531

Lomas, T., Ivtzan, I., \& Fu, C. (2015). A systematic review of the neurophysiology of mindfulness on EEG oscillations. Neuroscience \& Biobehavioral Reviews, 57, 401410. doi: 10.1016/j.neubiorev.2015.09.018

Lomas, T., Medina, J. C., Ivtzan, I., Rupprecht, S., Hart, R., \& Eiroa-Orosa, F. J. (2017). The impact of mindfulness on wellbeing and performance in the workplace: An inclusive systematic review of the empirical literature. European Journal of Work and Organizational Psychology, 26(4), 492-513. doi: 10.1080/1359432X.2017.1308924

Lomas, T., Medina, J. C., Ivtzan, I., Rupprecht, S., \& Eiroa-Orosa, F. J. (2017). The impact of mindfulness on the wellbeing and performance of educators: A systematic review of the empirical literature. Teaching and Teacher Education, 61, 132-141. doi: 10.1016/j.tate.2016.10.008

Lomas, T., Medina, J. C., Ivtzan, I., Rupprecht, S., \& Eiroa-Orosa, F. J. (2018). A systematic review of the impact of mindfulness on the wellbeing of healthcare professionals. Journal of Clinical Psychology, 7(3), 319-355. doi: 10.1002/jclp.22515

Ma, S. H., \& Teasdale, J. D. (2004). Mindfulness-based cognitive therapy for depression: Replication and exploration of differential relapse prevention effects. Journal of Consulting and Clinical Psychology, 72(1), 31-40. doi: 10.1037/0022-006X.72.1.31 
Running title: Mindfulness in the workplace

* Mackenzie, C. S., Poulin, P. A., \& Seidman-Carlson, R. (2006). A brief mindfulness-based stress reduction intervention for nurses and nurse aides. Applied Nursing Research, 19(2), 105-109. doi: 10.1016/j.apnr.2005.08.002

Malarkey, W. B., Jarjoura, D., \& Klatt, M. (2013). Workplace based mindfulness practice and inflammation: a randomized trial. Brain, Behavior, and Immunity, 27, 145-154.

* Manotas, M., Segura, C., Eraso, M., Oggins, J., \& McGovern, K. (2014). Association of brief mindfulness training with reductions in perceived stress and distress in Colombian health care professionals. International Journal of Stress Management, 21(2), 207-225. doi: $10.1037 / \mathrm{a} 0035150$

* Martín-Asuero, A., Queraltó, J. M., Pujol-Ribera, E., Berenguera, A., Rodriguez-Blanco, T., \& Epstein, R. M. (2014). Effectiveness of a mindfulness education program in primary health care professionals: A pragmatic controlled trial. Journal of Continuing Education in the Health Professions, 34(1), 4-12. doi: 10.1002/chp.21211

Maslach, C., Jackson, S., \& Leiter, M. (1986). Maslach Burnout Inventory Manual. Palo Alto, CA: Consult. Psychol. Press.

Matrix (2013). Economic analysis of workplace mental health promotion and mental disorder prevention programmes and of their potential contribution to EU health, social and economic policy objectives. Luxembourg: Executive Agency for Health and Consumers.

Matthews, G. (2016). Distress. In G. Fink (Ed.), Stress: Concepts, Cognition, Emotion, and Behavior (pp. 219-226). San Diego: Academic Press.

* McConachie, D. A. J., McKenzie, K., Morris, P. G., \& Walley, R. M. (2014). Acceptance and mindfulness-based stress management for support staff caring for individuals with intellectual disabilities. Research in Developmental Disabilities, 35(6), 1216-1227. doi: 10.1016/j.ridd.2014.03.005 
Running title: Mindfulness in the workplace

Moher, D., Liberati, A., Tetzlaff, J., \& Altman, D. G. (2009). Preferred Reporting Items for Systematic Reviews and Meta-Analyses: The PRISMA Statement. PLoS Medicine, 6(7), e1000097. doi: doi:10.1371/journal.pmed.1000097

Motowidlo, S. J. (2003). Job performance. In W. C. Borman, D. R. Ilgen, \& R. J. Klimoski (Eds.), Handbook of psychology: Industrial and organizational psychology, Vol. 12: Industrial and organizational psychology (pp. 39 -53). Hoboken, NJ: John Wiley \& Sons.

National Collaborating Centre for Methods and Tools (2008). Quality Assessment Tool for Quantiative Studies (QATQS). Hamilton, ON: McMaster University.

Neff, K. D. (2003). Self-compassion: An alternative conceptualization of a healthy attitude toward oneself. Self and Identity, 2(2), 85-101. doi: 10.1080/15298860309032

Office for National Statistics (2014). Full Report: Sickness Absence in the Labour Market. London: Office for National Statistics.

* Pipe, T. B., Bortz, J. J., Dueck, A., Pendergast, D., Buchda, V., \& Summers, J. (2009). Nurse leader mindfulness meditation program for stress management: a randomized controlled trial. Journal of nursing administration, 39(3), 130-137.

Pollard, E. L., \& Davidson, L. (2001). Foundations of Child Wellbeing. Paris: UNESCO.

R Core Team (2017). R: A language and environment for statistical computing. Vienna, Austria: R Foundation for Statistical Computing. Retrieved from https://www.Rproject.org/

* Roeser, R. W., Schonert-Reichl, K. A., Jha, A., Cullen, M., Wallace, L., Wilensky, R., .. . Harrison, J. (2013). Mindfulness training and reductions in teacher stress and burnout: Results from two randomized, waitlist-control field trials. Journal of Educational Psychology, 105(3), 787-804. doi: 10.1037/a0032093

Schwarzer, G. (2007). meta: An R package for meta-analysis. R News, 7(3), 40-45. 
Running title: Mindfulness in the workplace

Sedgwick, P., \& Marston, L. (2013). Meta-analyses: standardised mean differences. BMJ, 347(dec06 1), f7257-f7257. https://doi.org/10.1136/bmj.f7257.

Segal, J., Williams, M. G., \& Teasdale, J. D. (2002). Mindfulness-Based Cognitive Therapy for Depression: A New Approach to Preventing Relapse. New York: Guilford.

Seymour, V. (2016). The Human-Nature Relationship and Its Impact on Health: A Critical Review. Frontiers in Public Health, 4(260). doi: 10.3389/fpubh.2016.00260

* Shapiro, S. L., Astin, J. A., Bishop, S. R., \& Cordova, M. (2005). Mindfulness-based stress reduction for health care professionals: Results from a randomized trial. International Journal of Stress Management, 12(2), 164-176. doi: 10.1037/1072-5245.12.2.164

Shapiro, S. L., Carlson, L. E., Astin, J. A., \& Freedman, B. (2006). Mechanisms of mindfulness. Journal of Clinical Psychology, 62(3), 373-386. doi: 10.1002/jclp.20237

* Shapiro, S. L., Schwartz, G. E., \& Bonner, G. (1998). Effects of mindfulness-based stress reduction on medical and premedical students. Journal of Behavioral Medicine, 21(6), 581-599. doi: 10.1023/A:1018700829825

Shin, D. C., \& Johnson, D. M. (1978). Avowed happiness as an overall assessment of the quality of life. Social Indicators Research, 5(1-4), 475-492. doi: 10.1007/BF00352944

* Shonin, E., Van Gordon, W., Dunn, T. J., Singh, N. N., \& Griffiths, M. D. (2014). Meditation Awareness Training (MAT) for Work-related Wellbeing and Job Performance: A Randomised Controlled Trial. International Journal of Mental Health and Addiction, 12(6), 806-823.

* Song, Y., \& Lindquist, R. (2015). Effects of mindfulness-based stress reduction on depression, anxiety, stress and mindfulness in Korean nursing students. Nurse Education Today, 35(1), 86-90. doi: 10.1016/j.nedt.2014.06.010

* Sood, A., Sharma, V., Schroeder, D. R., \& Gorman, B. (2014). Stress Management and Resiliency Training (SMART) program among Department of Radiology faculty: a 
Running title: Mindfulness in the workplace

pilot randomized clinical trial. Explore $(N Y)$, 10(6), 358-363. doi: 10.1016/j.explore.2014.08.002

Spielberger, C. D., Gorsuch, R. L., \& Lushene, R. E. (1970). Manual for the State-Trait Anxiety Inventory (Self-Evaluation Questionnaire). Palo Alto, CA: Consulting Psychologists Press.

Tan, L., Wang, M.-J., Modini, M., Joyce, S., Mykletun, A., Christensen, H., \& Harvey, S. B. (2014). Preventing the development of depression at work: a systematic review and meta-analysis of universal interventions in the workplace. BMC medicine, 12(1), 74. doi: $10.1186 / 1741-7015-12-74$

Tang, Y.-Y., Ma, Y., Wang, J., Fan, Y., Feng, S., Lu, Q., . . Posner, M. I. (2007). Short-term meditation training improves attention and self-regulation. Proceedings of the National Academy of Sciences, 104(43), 17152-17156. doi: 10.1073/pnas.0707678104

* Taylor, C., Harrison, J., Haimovitz, K., Oberle, E., Thomson, K., Schonert-Reichl, K., \& Roeser, R. W. (2015). Examining Ways That a Mindfulness-Based Intervention Reduces Stress in Public School Teachers: a Mixed-Methods Study. Mindfulness, 7(1), 115-129. doi: 10.1007/s12671-015-0425-4

The Health \& Social Care Information Centre (2009). Adult psychiatric morbidity in England, Results of a household survey. London: The Health \& Social Care Information Centre.

* van Berkel, J., Boot, C. R. L., Proper, K. I., Bongers, P. M., \& van der Beek, A. J. (2014a). Effectiveness of a worksite mindfulness-based multi-component intervention on lifestyle behaviors. International Journal of Behavioral Nutrition and Physical Activity, 11(9).

* van Berkel, J., Boot, C. R. L., Proper, K. I., Bongers, P. M., \& van der Beek, A. J. (2014b). Effectiveness of a Worksite Mindfulness-Related Multi-Component Health Promotion 
Running title: Mindfulness in the workplace

Intervention on Work Engagement and Mental Health: Results of a Randomized Controlled Trial. PLoS One, 9(1), e84118. doi: 10.1371/journal.pone.0084118

van Dam, N. T., Sheppard, S. C., Forsyth, J. P., \& Earleywine, M. (2011). Self-compassion is a better predictor than mindfulness of symptom severity and quality of life in mixed anxiety and depression. Journal of Anxiety Disorders, 25(1), 123-130.

van Dam, N. T., van Vugt, M. K., Vago, D. R., Schmalzl, L., Saron, C. D., Olendzki, A., . . . Gorchov, J. (2018). Mind the hype: A critical evaluation and prescriptive agenda for research on mindfulness and meditation. Perspectives on Psychological Science, 13(1), $36-61$.

Virgili, M. (2015). Mindfulness-Based Interventions Reduce Psychological Distress in Working Adults: a Meta-Analysis of Intervention Studies. Mindfulness, 6(2), 326-337. doi: 10.1007/s12671-013-0264-0

Vøllestad, J., Sivertsen, B., \& Nielsen, G. H. (2011). Mindfulness-based stress reduction for patients with anxiety disorders: Evaluation in a randomized controlled trial. Behaviour Research and Therapy, 49(4), 281-288. doi: 10.1016/j.brat.2011.01.007

Watson, D., Clark, L. A. C., \& Tellegen, A. (1988). Development and validation of brief measures of positive and negative affect: The PANAS scales. Journal of Personality and Social Psychology, 54, 1063-1070. doi: 10.1037/0022-3514.54.6.1063

Weare, K. (2014). Evidence for Mindfulness: Impacts on the Wellbeing and Performance of School Staff. Exeter; Southampton: Universities of Exeter and Southampton.

Webster (1988) Webster's II New Riverside University Dictionary. Boston, MA, Houghton Mifflin.

* West, C. P., Dyrbye, L. N., Rabatin, J. T., Call, T. G., Davidson, J. H., Multari, A., ... Shanafelt, T. D. (2014). Intervention to promote physician well-being, job satisfaction, 
Running title: Mindfulness in the workplace

and professionalism a randomized clinical trial. JAMA internal medicine, 174(4), 527533. doi: 10.1001/jamainternmed.2013.14387

Wilson, J. (2014). Mindful America: Meditation and the mutual transformation of Buddhism and American culture. Oxford: Oxford University Press.

Windle, G. (2011). What is resilience? A review and concept analysis. Reviews in Clinical Gerontology, 21(2), 152-169.

* Wolever, R. Q., Bobinet, K. J., McCabe, K., Mackenzie, E. R., Fekete, E., Kusnick, C. A., \& Baime, M. (2012). Effective and viable mind-body stress reduction in the workplace: A randomized controlled trial. Journal of Occupational Health Psychology, 17(2), 246258. doi: $10.1037 / \mathrm{a} 0027278$

World Health Organization (1948). Preamble to the Constitution of the World Health Organization as Adopted by the International Health Conference, New York, 19-22 June, 1946

World Health Organization (2018). Depression: Facts Sheets. Available from: http://www. who.int/mental_health/management/depression/en/. Accessed on 2018 May 11; Last updated on 2017 Feb 02. 